\title{
Characteristics of Australian cohort study participants who do and do not take up an additional invitation to join a long-term biobank: The 45 and Up Study
}

Emily Banks ${ }^{1,2^{*}}$, Nicol Herbert ${ }^{2}$, Tanya Mather ${ }^{1}$, Kris Rogers ${ }^{2}$ and Louisa Jorm ${ }^{2,3}$

\begin{abstract}
Background: Large-scale population biobanks are critical for future research integrating epidemiology, genetic, biomarker and other factors. Little is known about the factors influencing participation in biobanks. This study compares the characteristics of biobank participants with those of non-participants, among members of an existing cohort study.

Methods: Individuals aged 45 and over participating in The 45 and Up Study and living $\leq 20 \mathrm{~km}$ from central Wagga Wagga, New South Wales (NSW), Australia (rural/regional area) or $\leq 10 \mathrm{~km}$ from central Parramatta, NSW (urban area) ( $n=2340)$ were invited to join a biobank, giving a blood sample and having additional measures taken, including height, weight, waist circumference, heart rate and blood pressure.

Results: The overall uptake of the invitation to participate was 33\% (762/2340). The response rate was $41 \%$ (410/1002) among participants resident in the regional area, and 26\% (352/1338) among those resident in the urban area. Characteristics associated with significantly decreased participation were being aged 80 and over versus being aged 45-64 (participation rate ratio: $\mathrm{RR}=0.45,95 \% \mathrm{Cl} 0.34-0.60$ ), not being born in Australia versus being born in Australia $(0.69,0.59-0.81)$, having versus not having a major disability $(0.54,0.38-0.76)$, having full-time caregiving responsibilities versus not being a full-time carer $(0.62,0.42-0.93)$ and being a current smoker versus never having smoked $(0.66,0.50-0.89)$. Factors associated with increased participation were being in part-time work versus not being in paid work $(1.24,1.07-1.44)$ and having an annual household income of $\geq \$ 50,000$ versus $<\$ 20,000(1.50,1.26-1.80)$.

Conclusions: A range of socio-economic, health and lifestyle factors are associated with biobank participation among members of an existing cohort study, with factors relating to health-seeking behaviours and access difficulties or time limitations being particularly important. If more widespread participation in biobanking is desired, particularly to ensure sufficient numbers among those most affected by these issues, specific efforts may be required to increase participation in certain groups such as migrants, the elderly, and those in poor health. Whilst caution should be exercised when generalising estimates of absolute prevalence from biobanks, estimates for many internal comparisons are likely to remain valid.
\end{abstract}

\footnotetext{
*Correspondence: Emily.Banks@anu.edu.au

${ }^{1}$ National Centre for Epidemiology and Population Health, Australian National University, Canberra, Australia

${ }^{2}$ The Sax Institute, Sydney, Australia

Full list of author information is available at the end of the article
} 


\section{Background}

In recent years, researchers have sought to integrate genetic and other biomarker data with epidemiological data by obtaining biospecimens from participants in large-scale cohort studies. However, participation rates in biobank studies vary considerably [1-8] and are generally lower than for non-biomarker oriented research [2]. The limited evidence available suggests that older individuals, ethnic minorities, and those without a family history of illness are less likely to donate to biobanks than other potential participants [3,5,6]. Despite its implications for prevalence estimates and other aspects of biobank metholodogy, how participation relates to broader demographic, health and lifestyle factors is not known. This study investigates the relation of demographic, lifestyle and other personal characteristics, to participation in a biobank among members of an existing cohort study.

\section{Methods \\ Overview}

The 45 and Up Study is a large scale study of healthy ageing involving men and women aged 45 years and over from the general population of New South Wales (NSW), Australia and is described in detail elsewhere [9]. Briefly, from February 2006 to April 2009, men and women from the general population of NSW were sampled through the Medicare Australia database and joined the study by completing a postal questionnaire. They gave written informed consent for follow-up through repeated contact and linkage to population health databases. In keeping with many contemporary cohort studies with extensive linkage, the response rate for the 45 and Up Study as a whole is estimated to be $18 \%$ [9], with younger individuals, those living in major cities and men being underrepresented, compared to the general population [10]. Compared to a more representative population sample, cohort members were on average wealthier, less likely to smoke and more likely to have good, very good or excellent self-reported health [10].

The specific study described in this paper is known as the "Link-Up Study" and was conducted among a subset of 2340 individuals already taking part in The 45 and Up Study. Its primary aim was to compare response rates to an invitation to participate in a biobank according to different types of recruitment site, fasting status and reminder letter at an urban and regional location, using a randomised design. The results of the primary randomised analyses are reported elsewhere [11]; this paper focuses on the comparison of characteristics of those who did and did not take up the invitation to participate in the biobank.

\section{Procedure}

All 45 and Up Study participants who resided $\leq 20 \mathrm{~km}$ from central Wagga Wagga, NSW, Australia (a rural/ regional area) or $\leq 10 \mathrm{~km}$ from central Parramatta, NSW (an urban area) were invited to participate in this substudy. Eligible 45 and Up Study cohort members were sent a postal invitation to take part in the Link-Up Study, which included a covering letter from the 45 and Up Study, a participant information leaflet and a brief questionnaire. The consent form was on the reverse of the questionnaire. Participants gave consent for the collection, long-term storage and use of their blood sample for unspecified health research, including genetic research. Participants gave their consent on the understanding that they would not receive any direct results from tests on their blood sample. In addition, participants agreed to their questionnaire answers and biomarker data being combined with existing data from the 45 and Up Study, including the baseline questionnaire and linkage to various population health databases.

\section{Self-administered questionnaire}

Participants were instructed to complete the questionnaire prior to attending their designated collection site and return it when they attended to give a blood sample. The questionnaire was one A4 page, and repeated selected questions from The 45 and Up Study baseline questionnaire. Questions included the participant's date of birth, self reported height and weight, self-rated health, health events in the last 3 years, and the Medical Outcomes Score-Physical Functioning scale (MOS-PF). The data from this questionnaire were not used further in these analyses.

\section{Biospecimen collection}

Participants were randomised to donate biospecimens at either a dedicated clinic established specifically for the purposes of the Link-Up Study, or to attend at an existing local pathology centre (see [11] for details of this aspect of the study). The phlebotomists at each site took a $30 \mathrm{ml}$ blood sample from participants and measured height, weight, waist circumference, blood pressure and heart rate.

\section{5 and Up Study baseline questionnaire}

Information from the 45 and Up Study baseline questionnaire was used as the source of data to compare the characteristics of participants and non-participants in the Link-Up biobank and included: age; sex; education; country of origin (born in Australia/not born in Australia); whether a participant was caring for a sick or disabled family member or friend; self-report of assistance required with day-to-day tasks due to illness or disability; smoking status; body mass index; and physical limitations. Physical limitations were measured using the MOS-PF, which asks 
participants whether they are limited in their ability to perform vigorous and moderate physical activities and tasks such as: lifting shopping; climbing stairs; walking; bending, kneeling or stooping; and bathing or dressing [12]. This score was categorised into 4 groups: 100 (no physical limitations reported), 90-99, 60-89, and 0-59. Body mass index was calculated as the reported weight in kilograms divided by the reported height in metres, squared, and was classified according to World Health Organization criteria into underweight $\left(<18.5 \mathrm{kgm}^{-2}\right)$, normal weight $\left(18.5-24.9 \mathrm{kgm}^{-2}\right)$, overweight $\left(25.0-29.9 \mathrm{kgm}^{-2}\right)$ and obese $\left(\geq 30.0 \mathrm{kgm}^{-2}\right)$ [13].

\section{Outcome measures}

The primary outcome measure for this study was participation in the Link-Up Study, through attendance at a biospecimen collection site to provide a blood sample and giving written consent to participate in the biobank, including use of blood samples for genetic and other research. The proportion of invitees who went on to participate in this way in the Link-Up Study is termed the "response rate".

\section{Statistical methods}

Response rate was analysed using generalised linear model with a binomial distribution and a log link function (binomial regression) (proc genmod in SAS, v9.2 Cary NC, USA) with response (yes or no) as the outcome. Associations with exposure variables were expressed as a participation rate ratio. This model was used to examine which individual characteristics were associated with differences in response rates. This model was not initially stratified by area. Model fit was assessed using the deviance to compare the fitted model with the full or saturated model that provided a perfect fit to the data. Wald 95\% confidence intervals were calculated for rate ratio estimates, and the overall effect of a variable was assessed with a likelihood ratio test. Heterogeneity of the effect of personal variables on response rate between areas was assessed by sequentially adding an interaction term of area with each variable, and the effect assessed by a likelihood ratio test of the interaction.

\section{Ethics statement}

Ethical approval for the study was provided by the University of New South Wales, Human Research Ethics Committee, the Australian National University Human Research Ethics Committee, and the University of Western Sydney Human Research Ethics Committee.

\section{Results}

Overall response to the invitation to participate

The overall uptake of the invitation to participate in the Link-Up Study was 33\% (762/2340). The response rate was $41 \%(410 / 1002)$ among participants resident in the regional area (Wagga Wagga) and 26\% (352/1338) among those resident in the urban area (Parramatta) $(\mathrm{p}<0.0001)$.

\section{Response rate according to demographic, lifestyle and other factors}

Table 1 shows the response rate to the invitation to take part in the Link-Up Study among people already participating in the 45 and Up Study, according to a range of factors. No significant variation in response rate was observed according to sex, distance from collection site, time since joining the baseline 45 and Up Study and body mass index. Individuals aged 80 and over were significantly less likely to take part than younger individuals, as were those who were not born in Australia, compared to Australian-born individuals. People with a higher annual household income and those in part-time work were significantly more likely than others to take part. People who were caring full-time for a sick or disabled family member or friend were significantly less likely to take part in the Link-Up Study than people who did not have such caring responsibilities. Individuals needing help with day-to-day tasks because of a longterm disability or illness and those with a severe functional limitation due to their physical health were also significantly less likely to participate, compared to those without such disability. Compared to people who had never smoked, current smokers were less likely to take part. In the regional area, people with a tertiary education were significantly more likely to participate than those without a tertiary education; an attenuated relationship was observed in the urban area (p(interaction)= 0.049). None of the relationships with the other factors varied significantly between the urban and regional areas (data not shown).

\section{Discussion}

Among individuals already taking part in a cohort study, people who participated in an biobank, through donating a blood sample and having physical measurements taken, were, on average, significantly younger, wealthier, more educated, less disabled and more likely to be born in Australia, compared to cohort members who did not participate. Those in part-time work were more likely to participate, and smokers and those with caregiving responsibilities were less likely to participate than other cohort members. No significant variation in response rate was observed according to sex, distance from collection site, time since joining the baseline 45 and Up Study and body mass index.

Research has previously been undertaken to investigate whether individuals would be willing to participate in biobanking, using hypothetical scenarios [14-17]. Past 
Table 1 Response rate to the invitation to take part in the Link-Up Study, according to demographic, lifestyle and other factors

\begin{tabular}{|c|c|c|c|}
\hline \multirow[t]{2}{*}{ Characteristic } & Total & Participated & $\begin{array}{l}\text { Rate Ratio (crude) } \\
\text { of participation }\end{array}$ \\
\hline & $\mathbf{N}$ & N (\%) & $(95 \% \mathrm{Cl})$ \\
\hline
\end{tabular}

\begin{tabular}{llll}
\hline Distance of residence from collection centre \\
$<5 \mathrm{~km}$ & 1170 & $387(33 \%)$ & 1.00 \\
$\geq 5 \mathrm{~km}$ & 1170 & $375(32 \%)$ & $0.97(0.87-1.09)$
\end{tabular}

Time since joining The $\mathbf{4 5}$ and Up Study

$\begin{array}{llll}\text { Less than } 1 \text { year } & 1128 & 381(34 \%) & 1.00 \\ 1-<2 \text { years } & 855 & 278(33 \%) & 0.98(0.86-1.11) \\ 2 \text { years or more } & 357 & 103(29 \%) & 0.87(0.73-1.04) \\ \text { Age } & & & \\ 45-64 \text { yrs } & 1464 & 499(34 \%) & 1.00 \\ 65-79 \text { yrs } & 611 & 223(36 \%) & 1.07(0.95-1.21) \\ \geq 80 \text { yrs } & 265 & 40(15 \%) & 0.45(0.34-0.60) \\ \text { Sex } & & & \\ \text { Male } & 1107 & 348(31 \%) & 1.00 \\ \text { Female } & 1233 & 414(34 \%) & 0.94(0.84-1.06)\end{array}$

Educational qualifications

Wagga Wagga

$\begin{array}{llll}\text { Not Tertiary Educated } & 765 & 287(38 \%) & 1.00 \\ \begin{array}{l}\text { Tertiary Educated } \\ \text { Parramatta }\end{array} & 221 & 118(53 \%) & 1.37(1.18-1.60) \\ \begin{array}{l}\text { Not Tertiary Educated } \\ \text { Tertiary Educated }\end{array} & 971 & 244(25 \%) & 1.00 \\ \begin{array}{l}\text { Country of origin } \\ \text { Born in Australia }\end{array} & 1636 & 102(31 \%) & 1.20(0.99-1.46) \\ \text { Not born in Australia } & 644 & 154(23 \%) & 0.69(0.59-0.81)\end{array}$

Annual household pre-tax income

$\begin{array}{llll}<\$ 20,000 & 444 & 106(24 \%) & 1.00 \\ \$ 20,000-\$ 49,999 & 535 & 174(33 \%) & 1.37(1.12-1.68) \\ \geq \$ 50,000 & 1249 & 455(36 \%) & 1.50(1.26-1.80) \\ \text { Employment status } & & & \\ \text { Not in paid work } & 1021 & 309(30 \%) & 1.00 \\ \text { Part time paid work } & 433 & 160(37 \%) & 1.24(1.07-1.44) \\ \text { Full time paid work } & 837 & 282(34 \%) & 1.10(0.97-1.25) \\ \text { Carer status } & & & \\ \text { Not a full-time carer } & 2242 & 743(33 \%) & 1.00 \\ \text { Full-time carer } & 94 & 19(20 \%) & 0.62(0.42-0.93) \\ \text { Disability } & & & \\ \text { No major disability } & 2092 & 714(31 \%) & 1.00 \\ \text { Major disability } & 137 & 26(18 \%) & 0.54(0.38-0.76)\end{array}$

Table 1 Response rate to the invitation to take part in the Link-Up Study, according to demographic, lifestyle and other factors (Continued)

\begin{tabular}{llll}
\hline \multicolumn{2}{l}{ Physical functional limitations } & & \\
None & 719 & $242(34 \%)$ & 1.00 \\
Mild & 591 & $245(41 \%)$ & $1.22(1.06-1.39)$ \\
Moderate & 450 & $152(34 \%)$ & $1.00(0.85-1.18)$ \\
Severe & 352 & $72(20 \%)$ & $0.61(0.49-0.77)$ \\
Smoking status & & & \\
Never smoker & 1425 & $497(35 \%)$ & 1.00 \\
Current smoker & 159 & $37(23 \%)$ & $0.66(0.50-0.89)$ \\
Ex-smoker & 736 & $225(31 \%)$ & $0.88(0.78-1.00)$ \\
Body mass index & & & \\
Underweight & 38 & $9(24 \%)$ & $0.95(0.80-1.12)$ \\
Normal weight & 702 & $227(32 \%)$ & 1.00 \\
Overweight & 838 & $292(35 \%)$ & $1.08(0.94-1.24)$ \\
Obese & 516 & $158(31 \%)$ & $0.73(0.41-1.31)$ \\
\hline Not Numbers & &
\end{tabular}

Note: Numbers do not always add up to total due to missing values.

studies indicate that individuals may be reluctant to donate because of lack of personal relevance, concerns that their sample will be misused, and general distrust of biobanks or researchers $[1,18]$. However, data comparing the characteristics of individuals who actually do or do not participate in biobanks are limited. Consistent with results from this study, previous studies have found that ethnic minorities and older people are less likely than others to donate biospecimens for research [19-21]. We were unable to identify any studies that evaluated directly the influence of health and lifestyle characteristics on biobank participation; the factors we identified are similar to those that influence participation in research in general (e.g. "the healthy cohort effect") [22-24]. Overall, our findings suggest that individuals less engaged in healthseeking behaviours (e.g. smokers) were less likely to participate, as well as those potentially affected by access difficulties or time limitations, such as those with disabilities or carer responsibilities, or the elderly.

Participation rates and factors influencing participation in biobanks vary from study to study, and according to context $[1-4,8]$. Even with the immense resources of the UK Biobank, a response rate of $<10 \%$ was achieved. It has been suggested that those donating to biobanks should be representative of the general public [3]. Although this is generally seen as important for reliable estimates of point prevalence, experience to date indicates that this is unlikely to be practical on a large scale. Furthermore, participants do not need to be representative of the general population to make internal comparisons of relative risk within the cohort (i.e. to quantify associations between exposures and outcomes), 
which is generally the central purpose of large scale, long term biobanks. Such estimates of relative risk remain valid, even when the cohort is from a relatively select group $[10,25]$. Examples of highly selected, yet valid, internal comparisons include estimates of the relative risks of lung cancer for smokers versus non smokers, among British Doctors [26], and consistent estimates of breast cancer risk in users versus non users of the oral contraceptive pill, in a variety of cohort studies [27]. For this study, this means that although the absolute response rates to the invitation may not necessarily be generalisable to other studies, internal comparisons, including characteristics of responders versus non-responders, are likely to be both valid and generalisable [10,25]. More importantly, the implication for biobanks generally are that response rates and the characteristics of responders and non-responders may influence the generalisability of prevalence estimates from biobanks, but are less likely to be a problem for internal comparisons.

Another important consideration for long term biobanks is the need to include sufficient numbers of participants from specific population groups of interest to allow appropriately powered analyses. Our results indicate that certain groups are less likely to participate and strategies to enhance participation in these groups may be necessary to ensure appropriate heterogeneity in the biobank population. Such strategies could include targeted community-based recruitment of the elderly and migrant groups and home-based recruitment methods.

\section{Conclusions}

People participating in research studies involving biobanking differ from those who do not take part in a number of ways, and are generally in better health. In keeping with cohort studies in general, this means that caution should be exercised in generalising from estimates of absolute prevalence from biobank studies, however for many internal comparisons, estimates are likely to remain valid.

\section{Abbreviations \\ $\mathrm{Cl}$ : Confidence interval; MOS-PF: Medical Outcomes Score-Physical Functioning.}

\section{Competing interests}

The authors declare that they have no competing interests.

\section{Authors' contributions}

Study conception and design: EB, LJ. Study coordination and data collection: $\mathrm{NH}, \mathrm{EB}$. Biostatistical supervision and conduct of analyses: KR. Interpretation of analyses: EB, LJ, KR. Literature review: TM, NH. Drafting of manuscript: EB, $\mathrm{NH}, \mathrm{TM}$. Revision of manuscript for important intellectual content: $\mathrm{NH}, \mathrm{KR}$, TM, LJ. All authors read and approved the final manuscript.

\section{Acknowledgements}

The authors would like to thank the men and women participating in The 45 and Up Study and in the Link-Up Study. The 45 and Up Study is managed by The Sax Institute in collaboration with major partner Cancer Council New South Wales; and partners the National Heart Foundation of
Australia (NSW Division); NSW Ministry of Health; beyondblue: the national depression initiative; Ageing, Disability and Home Care, NSW Family and Community Services; the Red Cross Blood Service; and UnitingCare Ageing. This specific project was funded by The Cancer Council NSW. Emily Banks is supported by the National Health and Medical Research Council.

\section{Author details}

${ }^{1}$ National Centre for Epidemiology and Population Health, Australian National University, Canberra, Australia. ${ }^{2}$ The Sax Institute, Sydney, Australia. ${ }^{3}$ School of Medicine, University of Western Sydney, Sydney, Australia.

Received: 17 September 2012 Accepted: 21 November 2012

Published: 27 November 2012

\section{References}

1. Melas PA, Sjöholm LK, Forsner T, Edhborg M, Juth N, Forsell Y, Lavebratt C: Examining the public refusal to consent to DNA biobanking: empirical data from a Swedish population-based study. J Med Ethics 2010, 36(2):93-98.

2. Matsui K, Kita Y, Ueshima H: Informed consent, participation in, and withdrawal from a population based cohort study involving genetic analysis. J Med Ethics 2005, 31(7):385-392.

3. Lanfear DE, Jones PG, Cresci S, Tang F, Rathore SS, Spertus JA: Factors influencing patient willingness to participate in genetic research after a myocardial infection. Genome Med 2011, 3(6):1-8.

4. Levy D, Splansky GL, Strand NK, Atwood LD, Benjamin EJ, Blease S, Cupples LA, D'Agostino RB, Fox CS, Kelly-Hayes M, et al: Consent for genetic research in the Framingham heart study. Am J Med Genet $A$ 2010, 152A(5):1250-1256.

5. Ford BM, Evans JS, Stoffel EM, Balmaña J, Regan MM, Syngal S: Factors associated with enrollment in cancer genetics research. Canc Epidemiol Biomarkers Prev 2006, 15(7):1355-1359.

6. Bogner HR, Wittink MN, Merz JF, Straton JB, Cronholm PF, Rabins PV, Gallo JJ: Personal characteristics of older primary care patients who provide a buccal swab for apolipoprotein E testing and banking of genetic material: the spectrum study. Publ Health Genom 2004, 7(4):202-210.

7. Meschia JF, Merino JG: Willingness of ischemic stroke patients to donate DNA for genetic research: a systematic review. J Stroke Cerebrovasc Dis 2003, 12(5):228-231.

8. UK Biobank Coordinating Centre: UK biobank: report of the integrated pilot phase. Cheshire; 2006. http://www.ukbiobank.ac.uk/wp-content/uploads/ 2011/06/Pilot_report.pdf?phpMyAdmin=trmKQIYdjjnQlgJ\%2CfAzikMhEnx6.

9. Banks E, Redman S, Jorm L, Armstrong B, Bauman A, Beard J, Beral V, Byles J, Corbett S, Cumming R: Cohort profile: the 45 and Up study. Int J Epidemiol 2008, 37(5):941-947.

10. Mealing NM, Banks E, Jorm LR, Steel DG, Clements MS, Rogers KD: Investigation of relative risk estimates from studies of the same population with contrasting response rates and designs. BMC Med Res Methodol 2010, 10:26.

11. Banks E, Herbert N, Rogers K, Mather T, Jorm L: Randomised trial investigating the relationship of response rate for blood sample donation to site of biospecimen collection, fasting status and reminder letter: the 45 and Up study. BMC Med Res Methodol 2012, 12:147. doi:10.1186/1471-2288-12-147.

12. Hays RD, Liu H, Spritzer K, Cella D: Item response theory analyses of physical functioning items in the medical outcomes study. Med Care 2007, 45(5):S32-S38.

13. World Health Organization: Obesity: preventing and managing the global epidemic. Geneva: World Health Organization; 1998.

14. Kettis-Lindblad A, Ring L, Viberth E, Hansson MG: Genetic research and donation of tissue samples to biobanks. What do potential sample donors in the Swedish general public think? Eur J Publ Health 2006, 16(4):433-440.

15. Goddard KAB, Smith S, Chen C, McMullen C, Johnson C: Biobank recruitment: motivations for nonparticipation. Biopreservation Biobanking 2009, 7(2):119-121

16. Hoeyer K, Olofsson B-O, Mjörndal T, Lynöe N: Informed consent and biobanks: a population-based study of attitudes towards tissue donation for genetic research. Scand J Publ Health 2004, 32(3):224-229.

17. Wong ML, Chia KS, Yam WM, Teodoro GR, Lau KW: Willingness to donate blood samples for genetic research: a survey from a community in Singapore. Clin Genet 2004, 65(1):45-51. 
18. Bussey-Jones J, Garrett J, Henderson G, Moloney M, Blumenthal C, Corbie-Smith C: The role of race and trust in tissue/blood donation for genetic research. Genet Med 2010, 12(2):116-121.

19. Sanner JE, Frazier L: Factors that influence characteristics of genetic biobanks. J Nurs Scholarsh 2007, 39(1):25-29.

20. Neumark DE, Stommel M, Given CW, Given BA: Research design and subject characteristics predicting nonparticipation in a panel survey of older families with cancer. Nurs Res 2001, 50(6):363-368.

21. McQuillan GM, Porter KS: Consent for future genetic research: the NHANES experience in 2007-2008. IRB 2011, 33(1):9-14.

22. Goldberg M, Chastang JF, Leclerc A, Zins M, Bonenfant S, Bugel I, Kaniewski $\mathrm{N}$, Schmaus A, Niedhammer I, Piciotti M, et al: Socioeconomic, demographic, occupational, and health factors associated with participation in a long-term epidemiologic survey: a prospective study of the French GAZEL cohort and its target population. Am J Epidemiol 2001, 154(4):373-384.

23. Lindsted KD, Fraser GE, Steinkohl M, Beeson WL: Healthy volunteer effect in a cohort study: temporal resolution in the Adventist health study. J Clin Epidemiol 1996, 49(7):783-790.

24. Zheng W, Chow W-H, Yang G, Jin F, Rothman N, Blair A, Li H-L, Wen W, Ji B-T, Li Q, et al: The shanghai Women's health study: rationale, study design, and baseline characteristics. Am J Epidemiol 2005, 162(11):1123-1131.

25. Manolio TA, Collins R: Enhancing the feasibility of large cohort studies. JAMA 2010, 304(20):2290-2291.

26. Doll R, Peto R, Boreham J, Sutherland I: Mortality in relation to smoking: 50 years' observations on male British doctors. BMJ 2004, 328(7455):1519.

27. Collaborative Group on Hormonal Factors in Breast Cancer: Breast cancer and hormonal contraceptives: collaborative reanalysis of individual data on 53297 with breast cancer and 100239 women without breast cancer from 54 epidemiological studies. Lancet 1996, 347:1713-1727.

doi:10.1186/1756-0500-5-655

Cite this article as: Banks et al:: Characteristics of Australian cohort study participants who do and do not take up an additional invitation to join a long-term biobank: The 45 and Up Study. BMC Research Notes 2012 5:655.

\section{Submit your next manuscript to BioMed Central and take full advantage of:}

- Convenient online submission

- Thorough peer review

- No space constraints or color figure charges

- Immediate publication on acceptance

- Inclusion in PubMed, CAS, Scopus and Google Scholar

- Research which is freely available for redistribution 